\title{
Portal vein embolization in children: As good as ALPPS
}

\author{
Barbara Elisabeth Wildhaber ${ }^{1}$ and Sylvain Terraz $^{2}$ \\ ${ }^{1}$ Swiss Pediatric Liver Centre, Department of Pediatrics, Gynecology and Obstetrics, \\ ${ }^{2}$ Unit of Interventional Radiology, Division of Radiology, Department of Diagnostics, \\ University Hospitals of Geneva, Geneva, Switzerland
}

Dear Editor,

We read with great interest the article "A minimally invasive first stage of ALPPS for hepatoblastoma in a child" by Akhaladze et al., ${ }^{1}$ reporting on a pediatric case where the authors successfully performed a laparoscopic ALPPS (Associating Liver Partition and Portal vein ligation for Staged hepatectomy) procedure to avoid post-hepatectomy liver failure after extended right hepatectomy for hepatoblastoma. Before ALPPS the future remnant liver (FRL) volume was $110.6 \mathrm{~cm}^{3}$ in a child of $11.5 \mathrm{~kg}(1.0 \%$ of body weight). Six days after the $1^{\text {st }}$ stage of ALPPS, FRL volume grew to $188.7 \mathrm{~cm}^{3}, 1.6 \%$ of body weight, corresponding to a $71 \%$ increase of FRL volume and allowing for a safe hepatectomy. We wish to congratulate the authors for this interesting report, yet have some considerations.

Even though ALPPS rapidly increases FRL, inducing 40 to $80 \%$ growth within six days, it is a very invasive procedure associated with high morbidity (16\% to $64 \%$ of adult patients) such as bile leakage and sepsis, and even mortality ( $12 \%$ to $23 \%$ of adult patients) due to hepatic insufficiency. ${ }^{2}$ In adults, portal vein embolization (PVE) by interventional radiology is also a common method to increase FRL, but has shown to be less efficient and needs more time for its effect. ${ }^{3}$ Yet, we herein wish to share our experience with PVE in children, where we used this method before extended right hepatectomy to increase the growth of the insufficient FRL. Three children, aged 14, 26 and 7 months, with a weight of $7.6,11.5$ and $6.9 \mathrm{~kg}$, respectively, all suffering from PRETEX III hepatoblastoma, treated with neo-adjuvant chemotherapy, underwent PVE between the third and fourth cycle of preoperative chemotherapy, i.e., four to six weeks before scheduled surgery. PVE was performed via an ipsilateral (right) transhepatic access, filling the right portal vein with a glue embolization agent in the two first cases, whereas the third case was done using an Amplatzer plug in the right portal vein with additional downstream glue agent. After PVE, the patients stayed in the hospital from 2 to 4 days. Descriptive data are reported in Table 1 . In summary, increase of FRL volume post-PVE ranged from $33 \%$ to $76 \%$. Four to six weeks after PVE right extended hepatectomy was performed in all cases without complications and children were discharged 7 to 10 days postoperatively.

Our results are encouraging and show that it may not be necessary to take the risk of ALPPS. If ever PVE fails, ALPPS might be used as a second line treatment. We strongly believe that PVE with interventional radiology in children is not only much less invasive, with a shorter time of intervention under general anesthesia, is less prone to complications, and thus causing less healthcare costs, but can also induce growth of the FRL with a similar efficacy as ALPPS. The waiting period of four to six weeks can easily be used for the last cycle of preoperative neoadjuvant chemotherapy and must not to be seen as a loss of time.

Received: January 11, 2021; Accepted: March 2, 2021

Corresponding author: Barbara Elisabeth Wildhaber

Chirurgie Pédiatrique, Hôpital des Enfants, Rue Willy Donzé 6, Genève 1211, Switzerland

Tel: +41-22-382-46-62, Fax: +41-22-382-46-66, E-mail: Barbara.Wildhaber@hcuge.ch

Copyright (C) 2021 by The Korean Association of Hepato-Biliary-Pancreatic Surgery

This is an Open Access article distributed under the terms of the Creative Commons Attribution Non-Commercial License (http://creativecommons.org/ licenses/by-nc/4.0) which permits unrestricted non-commercial use, distribution, and reproduction in any medium, provided the original work is properly cited. Annals of Hepato-Biliary-Pancreatic Surgery • pISSN: 2508-5778 • eISSN: 2508-5859 
Table 1. Descriptive data of children undergoing portal vein embolization

\begin{tabular}{cccccccc}
\hline Patient & Age (months) & Weight $(\mathrm{kg})$ & Initial FRL & post-PVE FRL & $\begin{array}{c}\text { Initial } \\
\text { FRL/body } \\
\text { weight }\end{array}$ & $\begin{array}{c}\text { Post-PVE } \\
\text { FRL/body } \\
\text { weight }\end{array}$ & $\begin{array}{c}\text { Increase of } \\
\text { FRL volume }\end{array}$ \\
\hline Case 1 & 14 & 7.6 & $118 \mathrm{~cm}^{3}$ & $208 \mathrm{~cm}^{3}$ & $1.5 \%$ & $2.7 \%$ & $+76 \%$ \\
Case 2 & 26 & 11.5 & $117 \mathrm{~cm}^{3}$ & $156 \mathrm{~cm}^{3}$ & $1.0 \%$ & $1.4 \%$ & $+33 \%$ \\
Case 3 & 7 & 6.9 & $72 \mathrm{~cm}^{3}$ & $124 \mathrm{~cm}^{3}$ & $1.0 \%$ & $1.7 \%$ & $+72 \%$ \\
\hline
\end{tabular}

FINANCIAL SUPPORT

None.

\section{DISCLOSURES}

None.

\section{CONFLICT OF INTEREST}

None.

\section{ORCID}

Barbara Elisabeth Wildhaber:

https://orcid.org/0000-0003-4548-382X

Sylvain Terraz: https://orcid.org/0000-0003-1539-8587

\section{AUTHOR CONTRIBUTIONS}

BEW: conception and design, analysis and interpretation of data, drafting the article, revising it critically for important intellectual content, final approval of the version to be published.

ST: conception and design, analysis and interpretation of data, revising it critically for important intellectual content, or on final approval of the version to be published.

\section{REFERENCES}

1. Akhaladze D, Uskova N, Rabaev G, Kachanov D, Grachev N. A minimally invasive first stage of ALPPS for hepatoblastoma in a child. Ann Hepatobiliary Pancreat Surg 2020;24:352-356.

2. Zhang GQ, Zhang ZW, Lau WY, Chen XP. Associating liver partition and portal vein ligation for staged hepatectomy (ALPPS): a new strategy to increase resectability in liver surgery. Int $\mathrm{J}$ Surg 2014;12:437-441.

3. Chan A, Zhang WY, Chok K, Dai J, Ji R, Kwan C, et al. ALPPS versus portal vein embolization for hepatitis-related hepatocellular carcinoma: a changing paradigm in modulation of future liver remnant before major hepatectomy. Ann Surg 2021;273:957-965. 